\title{
Fracture toughness determination of adhesive and co-cured joints in natural fibre composites
}

\author{
R.D.S.G. Campilho, D.C. Moura, D.J.S. Gonçalves, J.F.M.G. da Silva, M.D. Banea, L.F.M. da Silva
}

A B S T R A C T

Adhesive bonding has become more efficient in the last few decades due to the adhesives developments, granting higher strength and ductility. On the other hand, natural fibre composites have recently gained interest due to the low cost and density. It is therefore essential to predict the fracture behavior of joints between these materials, to assess the feasibility of joining or repairing with adhesives. In this work, the tensile fracture toughness $\left(G_{n}^{c}\right)$ of adhesive joints between natural fibre composites is studied, by bonding with a ductile adhesive and co-curing. Conventional methods to obtain $G_{\mathrm{n}}^{\mathrm{c}}$ are used for the co-cured specimens, while for the adhesive within the bonded joint, the $J$-integral is considered. For the $J$-integral calculation, an optical measurement method is developed for the evaluation of the crack tip opening and adherends rotation at the crack tip during the test, supported by a Matlab sub-routine for the automated extraction of these quantities. As output of this work, an optical method that allows an easier and quicker extraction of the parameters to obtain $G_{\mathrm{n}}^{\mathrm{c}}$ than the available methods is proposed (by the J-integral technique), and the fracture behaviour in tension of bonded and co-cured joints in jute-reinforced natural fibre composites is also provided for the subsequent strength prediction. Additionally, for the adhesively-bonded joints, the tensile cohesive law of the adhesive is derived by the direct method.

\section{Introduction}

The developments in adhesives technology made possible the use of adhesive bonding in many fields of engineering, such as automotive and aeronautical, because of higher peel and shear strengths, and ductility. As a result, bonded joints are replacing fastening or riveting [1]. More uniform stress fields, capability of fluid sealing, high fatigue resistance and the possibility to join different materials are other advantages of this technology. However, stress concentrations exist in bonded joints along the bond length owing to the gradual transfer of load between adherends and also the adherends rotation in the presence of asymmetric loads [2]. A large amount of works addresses the critical factors affecting the integrity of adhesive joints, such as the parent structure thickness, adhesive thickness, bonding length and geometric modifications that reduce stress concentrations [3-5]. On the other hand, natural fibre composites have recently gained interest and application, for instance in the construction or automotive industries, due to a few desirable properties such as low cost and density [6]. Thus, it is highly important the study of adhesive joints between these materials, to assess the feasibility of joining during the fabrication process of components (e.g. due to complex geometries), of joining cured parts of a structure or even for repairing purposes. Natural fibres like flax, henequen, sisal, coconut, jute, palm, bamboo, wood or paper have been used as reinforcement in thermosetting and thermoplastic resin composites [7]. Compared to typical fibre composites, e.g. with glass or carbon fibre reinforcements, natural fibres benefit from lower density, less machining wear during fabrication than mineral reinforcements, no health hazards, biodegradability, availability from natural and renewable sources and most importantly, they are cheaper per unit volume basis $[8,9]$. Natural fibres also provide a higher degree of design flexibility because they will bend rather than break during processing. However, their specific stiffness and strength do not match artificial fibres, and they suffer from high moisture absorption and poor wettability to some resins. Fabricated products in natural composites include door and trunk liners, parcel shelves, seat backs, interior sunroof shields and headrests [10]. The most commonly used 
matrix materials are polypropylene, polyester, polyurethane and epoxy. Most of the components made of natural fibre composites are fabricated by press-moulding, even though a large range of processes is currently feasible [11].

To expand the applications of natural fibre composites, the strength and failure mechanisms of bonded joints between these materials must be completely understood, by the availability of reliable design methodologies. The Finite Element Method (FEM) is the most accepted technique for the numerical strength prediction of bonded joints [12] by the calculation of stress and displacement fields, and combination with suitable failure criteria. Cohesive Zone Models (CZM), for instance, enable accurate fracture growth predictions [13]. CZM rely in the definition of the cohesive strength in tension and shear, $t_{\mathrm{n}}^{0}$ and $t_{\mathrm{s}}^{0}$, respectively (relating to the end of the elastic regime and beginning of damage), and the fracture toughness in tension and shear, $G_{\mathrm{n}}^{\mathrm{c}}$ and $G_{\mathrm{s}}^{\mathrm{c}}$ respectively (accounting for the amount of allowable plasticization prior to failure). A few methods are available to estimate the cohesive parameters and the respective laws: the property identification and inverse methods consist on assuming a simplified shape (bilinear or trilinear) for the fracture laws and defining the respective parameters by standardized procedures, while the direct method estimates the precise law shape by computing it based on fracture characterization data [14]. This is accomplished by the differentiation of the strain energy release rate in tension $\left(G_{n}\right)$ or shear $\left(G_{s}\right)$ with respect to the relative opening ( $\delta_{\mathrm{n}}$ for tension or $\delta_{\mathrm{s}}$ for shear). Carlberger and Stigh [15] estimated the cohesive laws of a thin layer adhesive in tension and shear by the direct method, using the Double-Cantilever Beam (DCB) and End-Notched Flexure (ENF) tests, respectively, considering $0.1 \leqslant t_{\mathrm{A}} \leqslant 1.6 \mathrm{~mm}\left(t_{\mathrm{A}}\right.$ is the adhesive thickness). The adherends rotation was measured by an incremental shaft encoder, whilst the crack tip opening was monitored by two Linear Variable Differential Transducers (LVDTs). The cohesive law was estimated by differentiation of the $J$-integral versus crack tip opening data.

This work evaluates the tensile fracture behaviour of adhesive joints between natural fibre composites, considering adhesivelybonding with a ductile polyurethane adhesive and co-curing. Conventional methods are used to obtain $G_{\mathrm{n}}^{\mathrm{c}}$ for the co-cured specimens, while for the adhesively-bonded joints, the $J$-integral is selected to account for the plasticity effects. For the $J$-integral, an optical measurement method is used for the evaluation of crack tip opening and adherends rotation at the crack tip, supported by a Matlab routine for the automated extraction of these parameters. Additionally, for the adhesively-bonded joints, the tensile cohesive law of the adhesive is derived by the direct method.

\section{Experimental work}

\subsection{Characterization of the materials}

The adherends used in this work consist of a jute-epoxy composite, with jute weave as reinforcement. The use of jute is related to the attractive strength and toughness properties of this reinforcement material (between $1 / 8$ and $1 / 4$ of E-glass fibres [16]) and wide use in several fields of industry, equally to flax, and showing higher stiffness than other common natural fibres such as Sisal [17]. Moreover, the specific gravity of jute is nearly half that of glass fibres ( $\approx 1.3$ compared to $\approx 2.5$ ), which makes it a viable replacement, allowing to match the stiffness of glass fibre components at a smaller weight (the stiffness of jute fibres is nearly $80 \%$ that of glass fibres [18]) and cost (the cost per weight of jute may achieve $1 / 9$ that of glass fibres). In general, as it is detailed in the work of Wambua et al. [8], natural fibre composites and jute are viable replacements for glass in many applications. In which concerns to chemical compatibility, jute can be combined with phenolic, epoxy and polyester resins to give unidirectional or woven layed up composites, or even laminated with glass to produce hybrid composites. Compatibility to other resins may require further treatments. A large amount of studies is available for the mechanical, thermal, rheological and impact characterization of jute fibres and their composites [8,16]. Typical properties of jute are as follows: density of $1.3-1.4 \mathrm{~g} / \mathrm{cm}^{3}$, elongation at failure of $1.5-1.8 \%$, tensile strength of $400-800 \mathrm{MPa}$ and Young's modulus (E) of 15-30 GPa. Epoxy was chosen for the matrix material on account of the good mechanical (strength and stiffness) and toughness properties, and also because of the superior wetting characteristics of epoxy on natural fibres and improved chemical stability to allow protection of the fibres against external agents [9]. The epoxy resin type SR 1500 and SD 2505 hardener from Sicomin Epoxy Systems were used, prepared by manual mixing of the two components by the recommended resin/hardener ratio. This particular resin was chosen due to its mechanical properties, demoulding characteristics and excellent adhesion to all types of fibres. The matrix properties, as specified by the manufacturer, are as follows: $E=3.1 \mathrm{GPa}$, tensile strength $\sigma_{\mathrm{f}}=74 \mathrm{MPa}$, strain at maximum load $\varepsilon_{\mathrm{m}}=4.4 \%$ and failure strain $\varepsilon_{\mathrm{f}}=6.0 \%$. The polyurethane adhesive SikaForce ${ }^{\circledR} 7888$, selected for the bonded joints, was characterized in the work of Neto et al. [19] by bulk tensile tests for the determination of $E, \sigma_{\mathrm{f}}$ and $\varepsilon_{\mathrm{f}}$, and DCB and ENF tests to define the values of $G_{\mathrm{n}}^{\mathrm{c}}$ and $G_{\mathrm{s}}^{\mathrm{c}}$, respectively. The bulk characterization was performed as specified in the EN ISO 527-2 standard. The obtained results gave $E=1.89 \pm 0.81 \mathrm{GPa}, \sigma_{\mathrm{f}}=28.60 \pm 2.0 \mathrm{MPa}$, $\varepsilon_{\mathrm{f}}=43.0 \pm 0.6 \%, \quad G_{\mathrm{n}}^{\mathrm{c}}=0.7023 \pm 0.1233 \mathrm{~N} / \mathrm{mm} \quad$ and $\quad G_{\mathrm{s}}^{\mathrm{c}}=8.721 \pm$ $0.792 \mathrm{~N} / \mathrm{mm}$.

\subsection{Joint geometries}

The geometry of the DCB specimens is shown in Fig. 1. The characteristic dimensions are the total length $L=160 \mathrm{~mm}$, initial crack length $a_{0} \approx 50 \mathrm{~mm}$, laminate thickness $h=5 \mathrm{~mm}$, width $B=15 \mathrm{~mm}$ and $t_{\mathrm{A}}=1 \mathrm{~mm}$. The adherends for the bonded specimens were made of jute-epoxy composite plates, consisting of eight stacked weave plies and a fibre volume fraction of approximately $30 \%$. The plates were fabricated by hand lay-up and cured at room temperature in a vacuum bag. The specimens were then cut in an automatic cutter with a diamond disc saw. The bonding process included manual abrasion with 220 grit sandpaper, cleaning with a proper degreaser and assembly in a steel mould. For a uniform value of $t_{\mathrm{A}}$, calibrated spacers of $1 \mathrm{~mm}$ were inserted between the adherends. These spacers were inserted at both bonding edges between the adherends to control the value of $t_{\mathrm{A}}$. For the calibrated spacer at the crack tip, 3 plies were stacked and glued together (making a total thickness of $1 \mathrm{~mm}$ ), composed of a $0.1 \mathrm{~mm}$ thick razor blade between $0.45 \mathrm{~mm}$ spacers, to create a pre-crack. The adhesive was then poured in both of the adherends of each specimen with a pneumatic gun after mixing in the adhesive nozzle, and the specimens were placed in a designed mould for the correct alignment during curing. The specimens were then left to cure before testing. After curing was completed, the steel spacers were removed with pliers, the specimens were slightly loaded in opening in the testing machine, and the value of $a_{0}$ was measured by a high resolution lens. This procedure extends the value of $a_{0}$ by $1-2 \mathrm{~mm}$ from the razor blade crack, and is highly relevant to prevent any blunting that could affect crack propagation at the initial stages. The co-cured specimens were fabricated by hand lay-up of 16 plies of jute weave and by placing a $70 \mathrm{~mm}$-length Melinex ${ }^{\circledR}$ Polyester Film with a thickness of $50 \mu \mathrm{m}$ at the symmetry plane of the plate to produce a pre-crack of approximately $50 \mathrm{~mm}$. Fabrication and curing of the plates were performed identically to the 8-ply plates. Pre-cracking prior to testing was also performed. For both speci- 

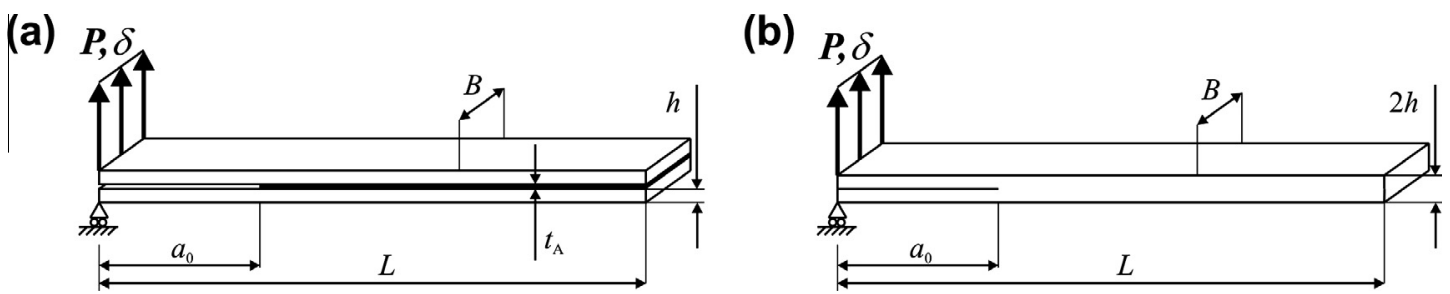

Fig. 1. Geometry and characteristic dimensions of the DCB bonded (a) and co-cured (b) specimens.

men types, stainless steel piano hinges were glued to both faces of the specimens at the cracked edge with a ductile adhesive, to provide a loading means in the testing machine grips. Also, a metric scale was glued with cyanoacrylate in both adherends to allow measurement of the crack length $(a)$ and of the input data for the extraction of the $J$-integral. Six specimens of each configuration were tested at room temperature and $2 \mathrm{~mm} / \mathrm{min}$ in an electromechanical testing machine (Shimadzu AG-X 100) with a load cell of $100 \mathrm{kN}$. Data recording was carried out at $5 \mathrm{~Hz}$ for the load $(P)$ and testing machine grips displacement $(\delta)$, registered during the test as a function of the time elapsed since its initiation. Pictures were recorded during the specimens testing with $5 \mathrm{~s}$ intervals using a 15 MPixel digital camera with no zoom and fixed focal distance to approximately $100 \mathrm{~mm}$. The camera was fixed to a rigid support at a distance of $100 \mathrm{~mm}$ from the specimen, facing the specimen. The metric scale was placed on the side of the specimen facing the camera to allow taking measures on the images acquired by the camera. Special care was taken to guarantee that the camera was parallel to the specimen and that the distance between the camera and the specimen was large enough to capture the region of interest of the specimen during the complete experiment. Since the camera was fixed, it is guaranteed that all the changes between images of the same test are due to the displacements and deformations of the specimen. This procedure allowed obtaining $a$, and the crack tip opening and rotation. The correlation of these values with the $P-\delta$ data was carried out by the time elapsed since the beginning of each test between the $P-\delta$ curve and each image.

\section{Reduction methods for $G_{n}^{c}$}

Different $G_{\mathrm{n}}^{\mathrm{c}}$ estimation techniques were considered for the co-cured and bonded specimens, due to the dissimilar failure behaviour. Actually, in the co-cured specimens, $G_{\mathrm{n}}^{\mathrm{c}}$ relates to an interlaminar fracture (brittle failure of the composite matrix, although with fibre bridging of the reinforcement fibres), while in the bonded specimens, fracture occurs along the adhesive bondline (ductile failure). In the first scenario, fracture occurred without significant plasticization and, as a result, it can be categorized under the scope of conventional Linear Elastic Fracture Mechanics (LEFM) based methods. When considerable plasticization exists, as it occurs for the second scenario in the adhesive layer, LEFM methods are rendered inaccurate [20] and the well known pathindependent $J$-integral is a feasible option to determine $G_{\mathrm{n}}^{\mathrm{c}}$. This technique is also more accurate than conventional industrial standards based on LEFM with correction factors to account for the non-linear behaviour of the materials (e.g. ASTM D3433-99:2005 and BS 7991:2001), and thus it is used in this work.

\subsection{Co-cured specimens}

Three methods were considered to evaluate $G_{\mathrm{n}}^{\mathrm{c}}$ : (1) the Compliance Calibration Method (CCM), based on the Irwin-Kies equation. Cubic polynomials in the form $C=C_{3} a^{3}+C_{2} a^{2}+C_{1} a+C_{0}$ were used to fit the $C=f(a)$ curves for the calculation of $\partial C / \partial a$ ( $C$ is the spec- imen compliance); (2) the Corrected Beam Theory (CBT), taking into account a crack length correction for rotation and deflection of the adherends at the crack tip, which was calculated from a linear regression analysis of $(C)^{1 / 3}$ versus $a$ data, and (3) the Compliance-Based Beam Method (CBBM), based on an equivalent crack, and depending only on the specimen's compliance during the test. Owing to the widespread use and knowledge about these techniques, detailed descriptions are not presented here, although these are available in the work of Banea et al. [21].

\subsection{Bonded specimens}

\subsubsection{Direct method to define $G_{\mathrm{n}}^{\mathrm{c}}$ and the CZM law}

In the proposed technique, the CZM law is measured by the direct method. Under this scope, the path-independence of the $J$-integral can be used to extract relations between the specimen loads and the cohesive law of the crack path [22]. Based on the fundamental expression for $J$ defined by Rice [23], it is possible to derive an expression for the value of $G_{\mathrm{n}}$ applied to the DCB specimen from the concept of energetic force and also the beam theory for this particular geometry, as follows (the following formulae are developed assuming that the $J$-integral gives a measurement of $\left.G_{n}\right)[24]$ :

$G_{\mathrm{n}}=12 \frac{\left(P_{\mathrm{u}} a\right)^{2}}{E h^{3}}+P_{\mathrm{u}} \theta_{\mathrm{o}} \quad$ or $\quad G_{\mathrm{n}}=P_{\mathrm{u}} \theta_{\mathrm{p}}$,

where $P_{\mathrm{u}}$ represents the applied load per unit width at the adherends edges, $\theta_{\mathrm{o}}$ the relative rotation of the adherends at the crack tip and $\theta_{\mathrm{p}}$ the relative rotation of the adherends at the loading line (Fig. 2). In this work, the first expression of (1) is considered, using $\theta_{\mathrm{o}}$ instead of $\theta_{\mathrm{p}}$, due to a simpler extraction of the parameter by the optical method. The $J$-integral can be calculated along an arbitrary path encircling the start of the adhesive layer, giving [22]:

$G_{\mathrm{n}}=\int_{0}^{\delta_{\mathrm{nc}}} t_{\mathrm{n}}\left(\delta_{\mathrm{n}}\right) d \delta_{\mathrm{n}}$

where $\delta_{\mathrm{nc}}$ is the end-opening at failure of the cohesive law (measured at the initial crack tip) and $t_{\mathrm{n}}$ is the current normal traction. $G_{\mathrm{n}}^{\mathrm{c}}$ can be considered the value of $G_{\mathrm{n}}$ at the beginning of crack growth. Thus, $G_{\mathrm{n}}^{\mathrm{c}}$ is given by the steady-state value of $G_{\mathrm{n}}$, at a $\delta_{\mathrm{n}}$ value of $\delta_{\mathrm{nc}}[15]$. The $t_{\mathrm{n}}\left(\delta_{\mathrm{n}}\right)$ curve can be easily obtained by differentiation of Eq. (1) with respect to $\delta_{\mathrm{n}}$

$t_{\mathrm{n}}\left(\delta_{\mathrm{n}}\right)=\frac{\partial G_{\mathrm{n}}}{\partial \delta_{\mathrm{n}}}$.

As a result, the procedure of an experiment is to measure the history of $P, a, \delta_{\mathrm{n}}$ and $\theta_{\mathrm{o}}$. The cohesive law in tension can then be estimated by plotting $G_{\mathrm{n}}$ in Eq. (1) or (2) as a function of $\delta_{\mathrm{n}}$, polynomial fitting of the obtained curve and differentiation [22].

\subsubsection{Optical method for the parameter measurement}

For calculating $\delta_{\mathrm{n}}$ and $\theta_{\mathrm{o}}$ for a given image, the optical method requires the identification of eight points (Fig. 3): two points $\left(p_{1}\right.$, $p_{2}$ ) for measuring the current $t_{\mathrm{A}}$ value at the crack tip $\left(t_{\mathrm{A}}^{\mathrm{CT}}\right)$ during 

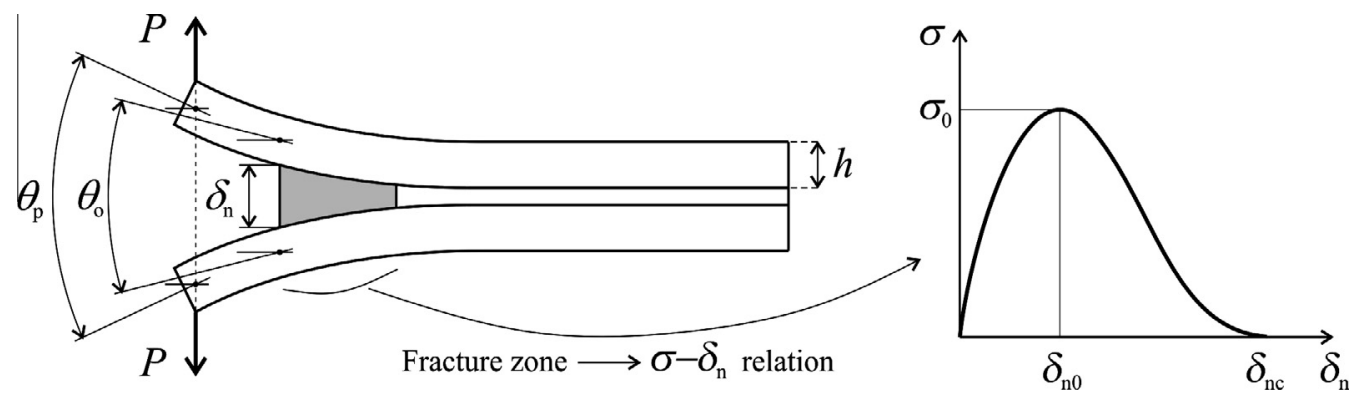

Fig. 2. DCB specimen under loading, with description of the analysis parameters.
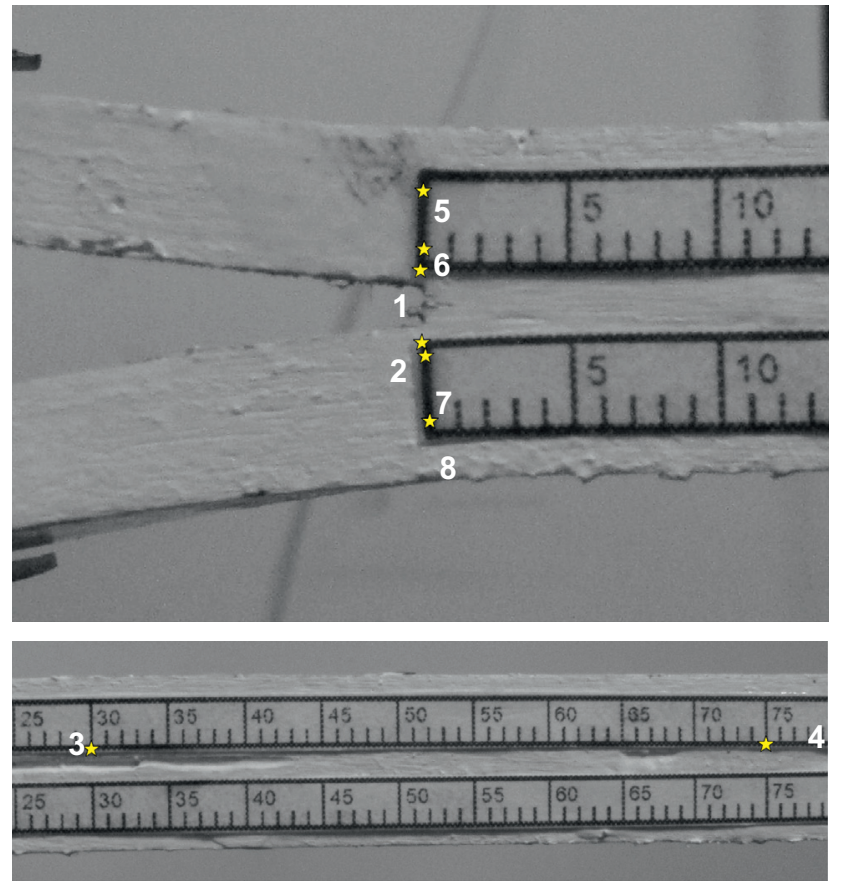

Fig. 3. Points taken by the optical method for measuring $\theta_{\mathrm{o}}$ and $G_{\mathrm{n}}^{\mathrm{c}}$

loading in image units (pixels), two points $\left(p_{3}, p_{4}\right)$ identifying a line segment in the image for which the length $(d)$ is known in real world units $(\mathrm{mm})$, two points $\left(p_{5}, p_{6}\right)$ on the top specimen and two points $\left(p_{7}, p_{8}\right)$ on the bottom specimen.

3.2.2.1. Points identification. All eight points are manually identified in the first picture of a trial using an in-house software tool. The identification of the points is aided by the ruler attached to the specimens, which helps finding their correct locations. Using the location of the points in the first picture, the points of the following pictures are automatically identified using a computer algorithm implemented in Matlab. Basically, for each point $p_{\mathrm{i}}$, a rectangular region centred in $p_{\mathrm{i}}$ is extracted from the first image forming a template $(t)$. This template describes the image pattern that surrounds the point and is used for locating the point in the next image. This is done by finding the position $(u, v)$ in the next image $(I)$ that has the highest normalized cross-correlation with the template. The normalized cross-correlation is a measure of similarity between two grayscale images that is invariant to linear changes in illumination and that quantifies the correlation between the grayscale levels of two images/regions [25]. This measure of similarity was chosen due to its low computational requirements, which is a critical factor given the high resolution of the images, and because changes in rotation and scale of the specimens are ex- pected to be small between two consecutive acquisitions (gapped by $5 \mathrm{~s}$ ). The normalized cross-correlation $(\gamma)$ of template $t$ with image $I$ at the position $(u, v)$ of image $I$ is defined as:

$$
\gamma(u, v)=\frac{\sum_{x, y}\left[f(x, y)-\bar{f}_{u, v}\right] \cdot[t(x-u, y-v)-\bar{t}]}{\left\{\sum_{x, y}\left[f(x, y)-\bar{f}_{u, v}\right]^{2} \cdot \sum_{x, y}[t(x-u, y-v)-\bar{t}]^{2}\right\}^{0.5}},
$$

where $f$ is the region of the image $I$ with the same size as $t$ centred in the position $(u, v)$. Calculating $\gamma$ for all the pixels of $I$ results in a matrix, where the maximum absolute value yields the location of the region in $I$ that has the highest correlation with $t$ and, thus, the most likely location of $p_{i}$ in the next image. This is done for every one of the eight points identified in the first image. After successfully identifying all the points of the second image, new templates are computed from the second image to search for the eight points in the third image, and so on until processing all the images.

3.2.2.2. Computation of $\delta_{n}$. The value of $t_{\mathrm{A}}^{\mathrm{CT}}$ in real world units (mm) is calculated as follows

$t_{\mathrm{A}}^{C T}=d \frac{\left|p_{1}-p_{2}\right|}{\left|p_{3}-p_{4}\right|}$,

assuming that the lens distortion is negligible, which is valid for pictures acquired with modern CCD cameras [26]. For all trials, a region of length $d=45 \mathrm{~mm}$ was used (Fig. 3). The pixel size was on average $0.024 \mathrm{~mm}$ and, thus, the estimated maximum error of the image acquisition process is $\pm 0.012 \mathrm{~mm}$. Finally, $\delta_{\mathrm{n}}$ can be defined as

$\delta_{\mathrm{n}}=t_{\mathrm{A}}^{C T}-t_{\mathrm{A}}$,

where $t_{\mathrm{A}}$ is the theoretical design value of $1 \mathrm{~mm}$. Since $t_{\mathrm{A}}$ can show small variations due to the fabrication process, an adjustment to $\delta_{\mathrm{n}}$ is also applied to make $\delta_{\mathrm{n}}=0$ at the beginning of the test (detailed in the Section 4).

3.2.2.3. Computation of $\theta_{o} . \theta_{\mathrm{o}}$ is calculated as the angle between lines $l_{1}$ and $l_{2}$ (Fig. 4). These lines could be directly calculated from points $\left(p_{5}, p_{6}\right)$ and $\left(p_{7}, p_{8}\right)$, respectively. However, for increasing robustness to small fluctuations of the point detection process, an image processing algorithm was used to extract the midline of the edge of the ruler that contains the pair of points in hand. In particular, a Difference of Gaussians filter was applied for enhancing the edges of the ruler, resulting in an image where pixels belonging to edges have high intensity values, while the remaining ones have low intensity (Fig. 4). Then, for the rows of the image between $p_{5}$ and $p_{6}$, the midpoint of the edge at each row is computed. The midpoint is first extracted for the row of $p_{5}$ by (1) collecting all the pixels to the left and to the right of $p_{5}$ that can be reached from $p_{5}$ without dropping the pixel intensity below a given threshold ( $10 \%$ for all experiments), and ( 2 ) by averaging the position of all the collected pixels weighted by the pixels 


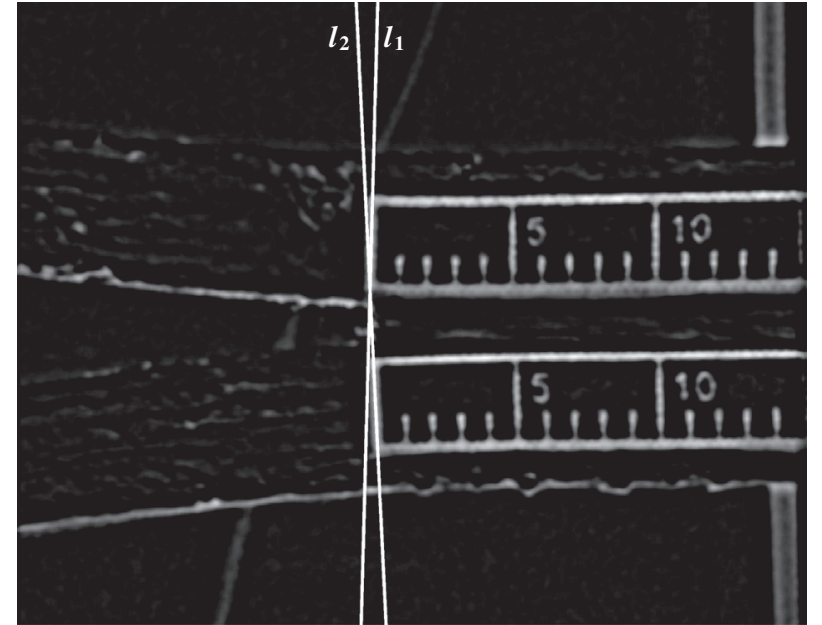

Fig. 4. Image after applying the Difference of Gaussians filter and the extracted lines $\left(l_{1}\right.$ and $\left.l_{2}\right)$ that are used for measuring $\theta_{0}$.

intensity value (so that pixels with higher intensities, i.e. pixels belonging to the edge, have a higher impact in the row's midpoint calculation). This makes the process robust to blur in the images and to the point identification process because points $p_{5}$ and $p_{6}$ do not need to be identified exactly at the midline of the edge. This process is repeated for all the following rows until reaching $p_{6}$, resulting in one point per row of the image between $p_{5}$ and $p_{6}$ that defines the midline of the edge of the ruler. Since these points are not necessarily collinear, a linear regression is used for obtaining $l_{1}$. The same process is repeated with points $\left(p_{7}, p_{8}\right)$ for obtaining $l_{2}$ and, finally, $\theta_{\mathrm{o}}$ may be calculated as the angle between the two lines

$\theta_{0}=\arccos \left(\frac{\vec{v}_{1} \cdot \vec{v}_{2}}{\left|\vec{v}_{1}\right|\left|\vec{v}_{2}\right|}\right)$

where $\vec{v}_{1}$ and $\vec{v}_{2}$ are the direction vectors of lines $l_{1}$ and $l_{2}$, respectively.

\section{Results}

\subsection{Co-cured specimens}

The interlaminar values of $G_{\mathrm{n}}^{\mathrm{c}}$ were calculated for the co-cured specimens by the previously mentioned techniques. Fig. 5 presents the experimental $R$-curve, relating the evolution of $G_{\mathrm{n}}$ with $a$, for one tested specimen, which is representative of the global results

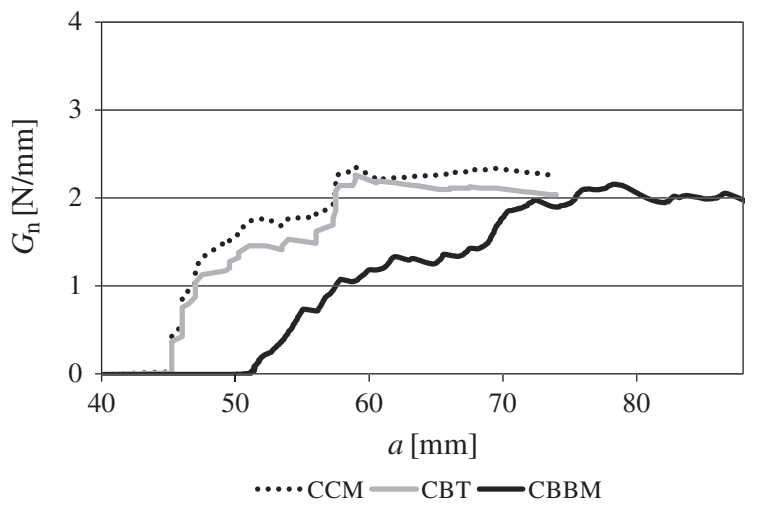

Fig. 5. Experimental $R$-curves by different methods for a representative DCB cocured specimen. for the co-cured specimens. The visible shifting in the CBBM $R$ curve, corresponding to bigger $a_{0}$ values than the CCM and CBT, is explained by the use of an equivalent crack to account for local plasticity, longer than the real value of $a$ measured during the tests and used in the other two methods [21]. Despite this fact, the three methods provide comparable results. For the presented specimen, $a_{0}$ was measured at $46.25 \mathrm{~mm}$, and this can be ascertained in Fig. 5 in the CCM and CBT plots at the initial stabilization of $G_{\mathrm{n}}$, which corresponds to crack initiation, although $G_{\mathrm{n}}$ subsequently continues to increase. The value of $a_{0}$ for the CBBM corresponded to $54.91 \mathrm{~mm}$, calculated directly from the $P-\delta$ data and relating to the first drop of $P$ in the corresponding $P-\delta$ curve. Disregarding the method, $G_{\mathrm{n}}$ increases from the initiation value, which is related to a fibre bridging event between the adherends while the crack grows. At a $G_{\mathrm{n}}$ value of approximately $2 \mathrm{~N} / \mathrm{mm}$, a marked steadystate value of $G_{n}$ is attained, corresponding to the stabilization of fibre bridging, i.e., balancing between breakage of "older" bridging fibres and creation of new ones at the crack front. Fig. 6 shows the crack growth process for one specimen during the development of fibre bridging, i.e., before attainment of the steady-state value of $G_{\mathrm{n}}$ (a) and during the steady-state phase (b). Table 1 summarizes the $G_{\mathrm{n}}^{\mathrm{c}}(\mathrm{N} / \mathrm{mm})$ values of the six co-cured specimens by the three methods, considering the crack initiation and stabilization values. The agreement between specimens is reasonably good for the CBT and the CBBM, although some deviations occur for the CCM. This can be accredited to difficulties in the estimation of the polynomial functions used to fit the $C=f(a)$ curves, required for $\partial C / \partial a$. Between methods, the correspondence is also quite good, especially when comparing the CBT and CBBM. With a similar justification, the CCM values show a bigger deviation.

\subsection{Bonded specimens}

Initially, $\theta_{\mathrm{o}}$ was estimated by the technique described in Section 3.2.2.3. Fig. 7 exemplifies the evolution of $\theta_{\mathrm{o}}$ for a particular test specimen, which will be used throughout this Section. The figure represents the raw curve, the 3rd degree polynomial fitting curve to reduce the noise and the corrected polynomial curve, adjusted to make $\theta_{\mathrm{o}}$ (testing time $=0$ ) $=0$. In each one of the tested specimens, the most suited degree was selected, by choosing the best correlation factor $(R)$ between 1st and 6th order polynomials (also applies to the forthcoming fitting data). The polynomial curve adjustment is required to subtract the data from the initial misalignment between glued scales in both adherends, whose markings were used to estimate $\theta_{\mathrm{o}}$. For the specimen of Fig. 7, this misalignment was approximately $1.33^{\circ}$. The value of $\delta_{\mathrm{n}}$ was also defined for each specimen (Section 3.2.2.2) during testing. Fig. 8 shows the raw curve from the optical measurements, the 3rd degree polynomial fitting curve and the adjusted curve. The curve shapes in Fig. 7 and Fig. 8 are consistent with the work of Ji et al. [27], with emphasis on the exponential shape of the $\delta_{\mathrm{n}}$-testing time plot. The final adjustment was carried out so that $\delta_{\mathrm{n}}($ testing time $=0)=0$. The need for this adjustment arises from small deviations to the design value of $t_{\mathrm{A}}=1 \mathrm{~mm}$. The values of $G_{\mathrm{n}}^{\mathrm{c}}$ for the bonded joints were defined by plotting the $G_{\mathrm{n}}-\delta_{\mathrm{n}}$ curves, considering $G_{\mathrm{n}}^{\mathrm{c}}$ as the steady-state value of $G_{\mathrm{n}}$ in the $G_{\mathrm{n}}-\delta_{\mathrm{n}}$ curve [15]. Fig. 9 plots the experimental $G_{\mathrm{n}}-\delta_{\mathrm{n}}$ law and the corresponding 6 th degree polynomial fitting curve. At the beginning of the test, $G_{\mathrm{n}}$ slowly increases with $\delta_{\mathrm{n}}$, but the growth rate of $G_{\mathrm{n}}$ rapidly increases up to nearly $\delta_{\mathrm{n}}=0.02-0.04 \mathrm{~mm}$, and a steady-state value of $G_{\mathrm{n}}$ is attained at approximately $\delta_{\mathrm{n}}=0.09 \mathrm{~mm}$. For this specimen, the measured value of $G_{\mathrm{n}}^{\mathrm{c}}$ is $1.429 \mathrm{~N} / \mathrm{mm}$. The experimental $G_{\mathrm{n}}-\delta_{\mathrm{n}}$ law was accurately represented by the fitting polynomial, in a similar fashion to all of the tested specimens ( $R$ varied between 0.96 and 0.99 ). For the six bonded specimens, the obtained data gave $G_{\mathrm{n}}^{\mathrm{c}}=1.182 \pm 0.215 \mathrm{~N} / \mathrm{mm}$. The reported values for this specific adhesive gave comparable results to previous tests by Neto et al. [19], 

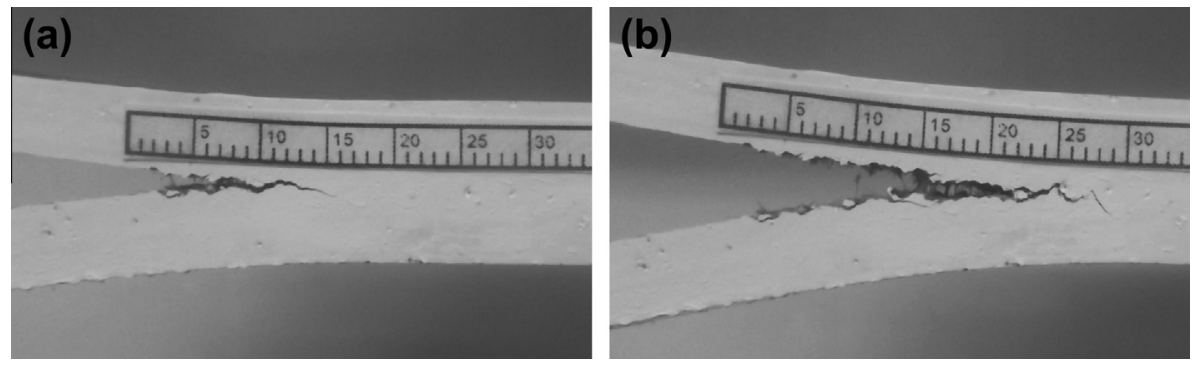

Fig. 6. Crack growth process in a co-cured specimen during the development of fibre bridging: before attainment of the steady-state value of $G_{\mathrm{n}}$ (a) and during the steadystate phase (b).

Table 1

$G_{\mathrm{n}}^{\mathrm{c}}(\mathrm{N} / \mathrm{mm})$ values of the six co-cured specimens by different methods.

\begin{tabular}{llllllll}
\hline \multirow{2}{*}{ Specimen } & \multicolumn{3}{l}{ Initiation } & & & \multicolumn{3}{l}{ Stabilization } \\
\cline { 2 - 3 } & CCM & CBT & CBBM & & CCM & CBT & CBBM \\
\hline 1 & 0.839 & 0.697 & 0.716 & & 2.370 & 1.990 & 1.685 \\
2 & 1.330 & 1.034 & 0.969 & & 2.103 & 2.524 & 2.114 \\
3 & 1.728 & 1.274 & 1.228 & & 2.245 & 1.973 & 1.842 \\
4 & 0.856 & 0.707 & 0.745 & & 2.810 & 1.759 & 1.655 \\
5 & 0.625 & 0.864 & 0.840 & & 2.615 & 1.753 & 1.528 \\
6 & 1.240 & 0.750 & 0.741 & & 2.285 & 2.105 & 2.065 \\
Average & 1.103 & 0.888 & 0.873 & & 2.405 & 2.017 & 1.815 \\
St. Dev. & 0.405 & 0.228 & 0.197 & 0.261 & 0.284 & 0.236 \\
\hline
\end{tabular}

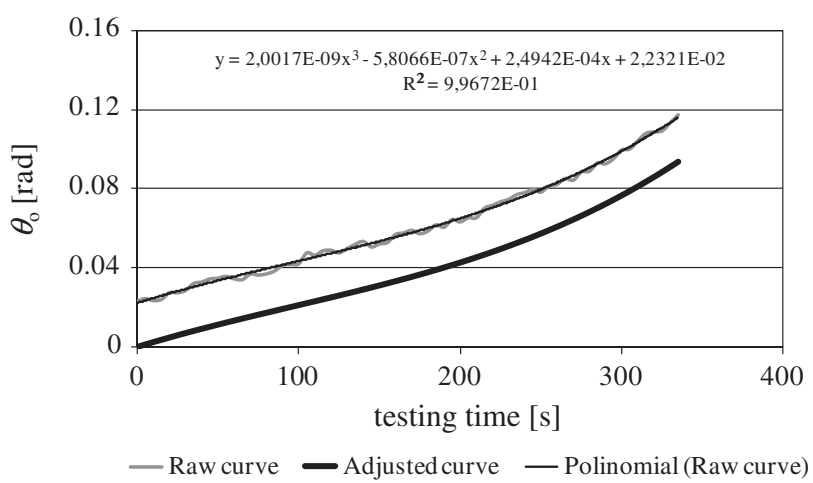

Fig. 7. Evolution of $\theta_{\mathrm{o}}$ for one test specimen: raw curve obtained from the optical method, polynomial fitting curve and corrected polynomial curve.

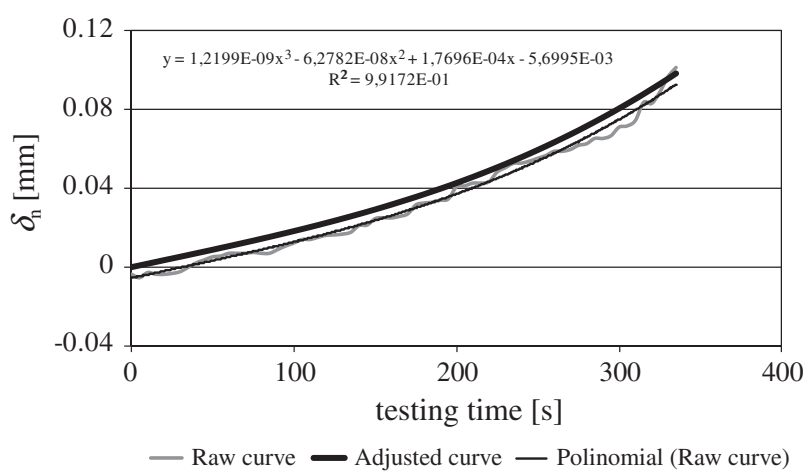

Fig. 8. Evolution of $\delta_{\mathrm{n}}$ for one test specimen: raw curve obtained from the optical method, polynomial fitting curve and corrected polynomial curve.

although slightly bigger (average of $G_{\mathrm{n}}^{\mathrm{c}}=1.182 \mathrm{~N} / \mathrm{mm}$ compared to $G_{\mathrm{n}}^{\mathrm{c}}=0.702 \mathrm{~N} / \mathrm{mm}$ ). This slight variation can be justified on one hand by different adherend constraining conditions, and on the other,

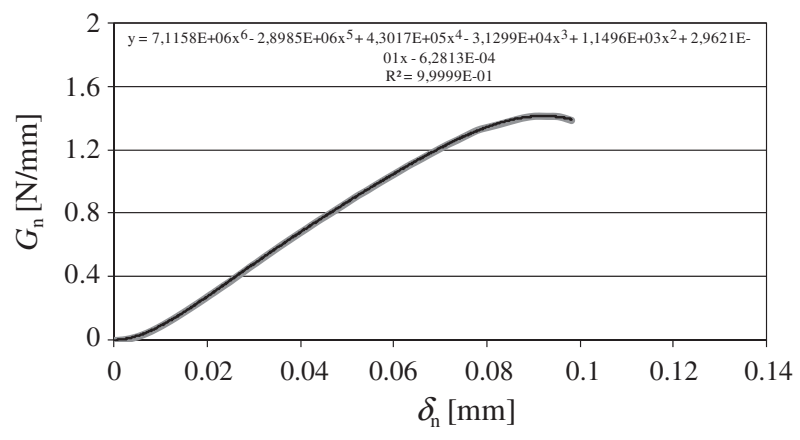

Fig. 9. Experimental $G_{\mathrm{n}}-\delta_{\mathrm{n}}$ law for one test specimen and polynomial fitting curve.

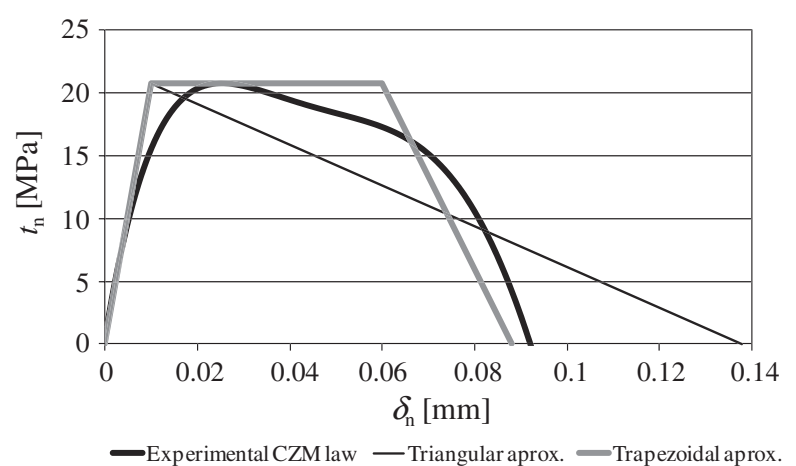

Fig. 10. Experimental $t_{n}-\delta_{\mathrm{n}}$ law for one test specimen.

since the method in the work of Neto et al. for prediction of $G_{n}^{c}$, although accounting for the adhesive plasticity, may slightly under predict $G_{\mathrm{n}}^{\mathrm{c}}$ as it is still LEFM-based. Fig. 10 shows the obtained experimental $t_{\mathrm{n}}-\delta_{\mathrm{n}}$ law, showing the ductile characteristics of the adhesive after the peak value of $t_{\mathrm{n}}$ is attained. For this specimen, the following values were found: $t_{\mathrm{n}}^{0}=20.73 \mathrm{MPa}$ and $\delta_{\mathrm{nc}}=0.0935 \mathrm{~mm}$. For the complete batch of tested specimens, average values and deviations were as follows: $t_{\mathrm{n}}^{0}=23.18 \pm 3.57 \mathrm{MPa}$ and $\delta_{\mathrm{nc}}=0.0843 \pm$ $0.0156 \mathrm{~mm}$. In the work of Neto et al. [19], comparable values of bulk strength in tension to $t_{\mathrm{n}}^{0}$ were found, i.e., $28.60 \pm 2.0 \mathrm{MPa}$. Proposed triangular and trapezoidal simplified CZM laws are also presented, allowing concluding that for the adhesive SikaForce ${ }^{\circledR} 7888$ a trapezoidal law is particularly suited, since it accounts the best for the adhesive ductility.

\section{Concluding remarks}

This work dealt with the determination of $G_{\mathrm{n}}^{\mathrm{c}}$ of adhesive joints between natural fibre composites, either bonding with a ductile 
polyurethane adhesive or co-curing. $G_{\mathrm{n}}^{\mathrm{c}}$ for the co-cured specimens was estimated by conventional fracture characterization techniques such as the CCM, CBT and CBBM. Results showed consistent $R$-curves between tested specimens and $G_{\mathrm{n}}^{\mathrm{c}}$ values for the three estimation methods. On account of the co-curing method, crack propagation was accompanied by large-scale fibre-bridging events between the adherends, which resulted on crack initiation at $G_{\mathrm{n}}^{\mathrm{c}} \approx 0.9 \mathrm{~N} / \mathrm{mm}$ and propagation at $G_{\mathrm{n}}^{\mathrm{c}} \approx 2 \mathrm{~N} / \mathrm{mm}$, after stabilization of the bridging process. For the bonded joints, the $J$-integral was used to measure $G_{\mathrm{n}}^{\mathrm{c}}$, given the large adhesive plasticity. With this purpose, an optical measurement and data analysis method was built in Matlab to extract $\theta_{\mathrm{o}}$ to obtain $G_{\mathrm{n}}$, and $\delta_{\mathrm{n}}$ to build the CZM laws. Average results gave $G_{\mathrm{n}}^{\mathrm{c}} \approx 1.2 \mathrm{~N} / \mathrm{mm}$, proving that at initiation, the bonded joint is tougher than the co-cured joint. However, in a relatively short propagation length, fibre bridging makes the co-cured joint tougher and more resistant to crack propagation. For the bonded joint, the complete tensile CZM law of the adhesive was derived by the direct method, on account of the available $G_{\mathrm{n}}-\delta_{\mathrm{n}}$ curve that was differentiated to provide the $t_{\mathrm{n}}-\delta_{\mathrm{n}}$ (or CZM) law. As it was expected, the CZM curves showed the large plasticity of the polyurethane adhesive. Approximations to triangular and trapezoidal simplified CZM laws, which are easy to implement in FEM software, showed that the trapezoidal law reproduces the experimental behaviour with a reasonable level of accuracy. As output of this work, the two bonding methods were compared and tensile fracture data was provided for the strength prediction of joints in natural fibre composites by CZM modelling or more conservative techniques that rely on fracture data in the respective failure criteria. For mixed-mode fracture, typical in bonded joints, complete shear characterization is necessary as well, which follows identical characterization methods than the ones proposed here, and whose estimation techniques are readily obtained in the literature. Likewise, mixed-mode criteria are usually needed to build a mixed-mode CZM law that simultaneously accounts for tension and shear during damage propagation.

\section{References}

[1] Lee MJ, Cho TM, Kim WS, Lee BC, Lee JJ. Determination of cohesive parameters for a mixed mode cohesive zone model. Int J Adhes Adhes 2010;30:322-8.

[2] Pinto AMG, Magalhães AG, Campilho RDSG, de Moura MFSF, Baptista APM. Single-lap joints of similar and dissimilar adherends bonded with an acrylic adhesive. J Adhes 2009;85:351-76.

[3] Campilho RDSG, Pinto AMG, Banea MD, Silva RF, da Silva LFM. Strength improvement of adhesively-bonded joints using a reverse-bent geometry. Adhes Sci Technol 2011;25:2351-68.

[4] Deng J, Lee MMK. Effect of plate end and adhesive spew geometries on stresses in retrofitted beams bonded with a CFRP plate. Compos: Part B 2008;39:731-9.
[5] Kim TH, Kweon JH, Choi JH. An experimental study on the effect of overlap length on the failure of composite-to-aluminum single-lap bonded joints. J Reinf Plast Compos 2008;27:1071-81.

[6] Ferreira JM, Silva H, Costa JD, Richardson M. Stress analysis of lap joints involving natural fibre reinforced interface layers. Compos: Part B 2005;36:1-7

[7] Varghese S, Kuriakose B, Thomas S. Stress relaxation in short sisal fiberreinforced natural rubber composites. J Appl Polym Sci 1994;53:1051-60.

[8] Wambua P, Ivens J, Verpoest I. Natural fibres: can they replace glass in fibre reinforced plastics? Compos Sci Technol 2003;63:1259-64.

[9] Herrera-Franco PJ, Valadez-González A. A study of the mechanical properties of short natural-fiber reinforced composites. Compos: Part B 2005;36:597-608.

[10] Suddell BC, Evans WJ. The increasing use and application of natural fibre composites materials within the automotive industry. In: Proceedings of the seventh international conference on woodfiber-plastic composites, Forest Products Society, Madison, USA; 2003.

[11] Plackett D. The natural fiber-polymer composite industry in Europetechnology and markets. In: Proceedings of the progress on woodfibreplastic composites conference 2002, University of Toronto, Toronto, Canada 2002.

[12] da Silva LFM, Campilho RDSG. Advances in numerical modelling of adhesive joints. Heidelberg: Springer; 2011.

[13] Liljedahl CDM, Crocombe AD, Wahab MA, Ashcroft IA. Damage modelling of adhesively bonded joints. Int J Fract 2006;141:147-61.

[14] Campilho RDSG, de Moura MFSF, Pinto AMG, Morais JJL, Domingues JJMS. Modelling the tensile fracture behaviour of CFRP scarf repairs. Compos: Part B 2009;40:149-57.

[15] Carlberger T, Stigh U. Influence of layer thickness on cohesive properties of an epoxy-based adhesive-an experimental study. J Adhes 2010;86:814-33.

[16] $\mathrm{Ku} \mathrm{H}$, Wang $\mathrm{H}$, Pattarachaiyakoop N, Trada $\mathrm{M}$. A review on the tensile properties of natural fiber reinforced polymer composites. Compos: Part B 2011;42:856-73.

[17] Schloesse T, Knothe J. Vehicle parts reinforced with natural fibres. Kunstst Plast Eur 1997;87:25-7.

[18] Roe PJ, Ansell MP. Jute-reinforced polyester composites. J Mater Sci 1985;20:4015-20.

[19] Neto JABP, Campilho RDSG, da Silva LFM. Parametric study of adhesive joints with composites. Int J Adhes Adhes 2012;37:96-101.

[20] Giovanola JH, Finnie I. A review of the use of the $J$ integral as a fracture parameter. Solid Mech Arch 1984;9:197-225.

[21] Banea MD, da Silva LFM, Campilho RDSG. Effect of temperature on tensile strength and mode I fracture toughness of a high temperature epoxy adhesive. J Adhes Sci Technol 2012;26:939-53.

[22] Stigh U, Alfredsson KS, Andersson T, Biel A, Carlberger T, Salomonsson K. Some aspects of cohesive models and modelling with special application to strength of adhesive layers. Int J Fatigue 2010;165:149-62.

[23] Rice JR. A path independent integral and the approximate analysis of strain concentration by notches and cracks. J Appl Mech 1968;35:379-86.

[24] Banea MD, da Silva LFM, Campilho RDSG. Temperature dependence of the fracture toughness of adhesively bonded joints. J Adhes Sci Technol 2010;24:2011-26.

[25] Lewis JP. Fast Template Matching, Vision Interface 95, Canadian image processing and pattern recognition society, Quebec City, Canada, May 1519; 1995. p. $120-123$

[26] Zhang Z. Camera calibration. In: Medioni G. Kang S, editors. Emerging topics in computer Vision, Prentice Hall Professional Technical Reference; 2004, [chapter 2].

[27] Ji G, Ouyang Z, Li G, Ibekwe S, Pang SS. Effects of adhesive thickness on global and local mode-I interfacial fracture of bonded joints. Int J Solids Struct 2010;47:2445-58. 